\title{
Fertility Scoring Index: CIMAR'S Novel System to Predict assisted Reproductive Technology Success
}

\author{
${ }^{1}$ Rochelle Heroina Gracias, ${ }^{2}$ Louis Fessy Thalakottoor, ${ }^{3}$ Parasuram Gopinath, ${ }^{4}$ Gopinathan Kannoly Karunakaran
}

\begin{abstract}
Background: About $15 \%$ of all couples are infertile and require fertility treatment. With constantly improving clinical and laboratory procedures, pregnancy rates of about $30 \%$ per transfer are routinely reported. In non-donor-oocyte cycles, the percentage of in vitro fertilization/intracytoplasmic sperm injection (IVF/ ICSI) cycles that result in pregnancy ranges from 18 to $45 \%$, depending on several factors (Society for Assisted Reproductive Technology 2009). But a patients concern is about the success rate-'What is my chance of getting pregnant'? For the success in IVF/ICSI-embryo transfer cycle there are many variables thought to be directly related to the implantation and successful outcome.
\end{abstract}

Aims and objectives:

1. To identify independent predictors ICSI outcome.

2. To make a composite predictive scoring system-

a. For patient selection and counseling for assisted reproductive technology (ART).

b. That may prove critical in counseling poor prognosis patients, about their prognosis or against IVF treatment (e.g. patients with least benefits in undergoing IVF can opt for donor oocytes/surrogacy, etc. without wasting a cycle in trial and error).

c. Optimizing treatment by developing more customized individually tailored treatment plan with consideration to predictive factors.

Study design: The research was approved by the institutional review board. A retrospective ongoing study was performed, over a period of 3 years at a well established infertility institution. A sample size of 1020 patients was considered from two hospitals of the same institution. The patients were stimulated by different protocols specific to each patients age, AFC, etc [Polycystic ovarian syndrome (PCOS) patients showing hyperresponse in follicular study-antagonist protocol]; though a majority underwent long agonist protocol. They were evaluated and the outcome was assessed through logistic regression analysis. Several variables were taken into consideration-to name a few; age, previous pregnancy outcome, previous ART treatment if any, E2/LH/P4 [baseline values and on the day of human chorionic gonadotropin (hCG)], etc. A preferential scoring was derived to obtain a predictive scoring for pregnancy outcome.

\footnotetext{
${ }^{1}$ Gynecologist, ${ }^{2}$ Coordinator, ${ }^{3}$ Consultant, ${ }^{4} \mathrm{Head}$

${ }^{1-3}$ Department of Infertility Medicine, Centre of Infertility Management and Assisted Reproduction, Kochi, Kerala, India

${ }^{4}$ Department of Obstetrics and Gynecology, Edappal Hospital Malappuram, Kerala, India
}

Corresponding Author: Rochelle Heroina Gracias, Gynecologist, Department of Infertility Medicine, Centre of Infertility Management and Assisted Reproduction, Kochi, Kerala India Phone: 00914844134444, e-mail: rochelle_gracias@hotmail.com
Results: A pregnancy predicting scoring was arrived at. On considering several variables, the cut off score represented a $50 \%$ success rate of IVF/ICSI cycle.

Conclusion: Bearing in mind that fertility is independent of hospital protocols and primarily dependent on the individual woman, the derived predictive scoring can be applied to individual cohort of patients under infertility treatment and has excellent discrimination ability for assessing the likelihood of pregnancy outcome. Application of this scoring will allow individualized treatment decision-making for patients under infertility treatment.

Keywords: Fertility scoring, Infertility, Pregnancy success, ART success.

How to cite this article: Gracias RH, Thalakottoor LF, Gopinath P, Karunakaran GK. Fertility Scoring Index: CIMAR'S Novel System to Predict Assisted Reproductive Technology Success. Int J Infertil Fetal Med 2014;5(2):44-57.

Source of support: Nil

Conflict of interest: None

Date of Received: 04-05-14

Date of Acceptance: 14-08-14

Date of Publication: May 2014

\section{INTRODUCTION}

About $15 \%$ of all couples are infertile and require treatment. ${ }^{1}$ Worldwide, the number of children born as a result of in vitro fertilization/intracytoplasmic sperm injection (IVF/ ICSI) already exceeds three million, ${ }^{2}$ since the birth of the first IVF infant 30 years ago. With improving clinical and laboratory procedures, pregnancy rates of about $30 \%$ per transfer are routinely reported. ${ }^{3}$

The percentage of IVF/ICSI cycles that result in pregnancy, in women using non-donor-oocytes range from about 18 to $45 \%$, depending on various factors (Society for Assisted Reproductive Technology 2009). Despite assisted reproductive technologies (ART) being a difficult, expensive, time and emotional expenditure to patients undergoing IVF/ICSI, they are interested in their likelihood of getting pregnant. Hence, identifying these predictors is inevitable in optimizing treatment and counseling the subfertile couple.

Success of IVF/ICSI-embryo transfer cycle depends on several variables: primarily on ovarian response to hormonal stimulation. Generally accepted in infertility medicine is the concept of diminished ovarian reserve. A variety of screening tests have been developed to provide a reliable assessment of the ovarian reserve and its response to gonadotropin stimulation but aging associated with progressive follicular 
depletion and diminished oocyte quality, a reduction in the cohort of follicles available to respond to gonadotropin stimulation ${ }^{4}$ is inevitable. Other predictors of ovarian response are ovarian volume ${ }^{5,6}$ the number of antral follicles, ${ }^{7,8}$ evaluation of ovarian stromal blood flow, ${ }^{9}$ assessment of serum FSH, ${ }^{10}$ $\mathrm{LH},{ }^{11}$ estradiol (E2) and anti-mullerian hormone. ${ }^{12}$ Other critical prognostic factors include: the number of previous treatment cycle, the number of former successful cycle and cycle cancellation. Semen quality is a factor that includes: sperm concentration, percentage of motility, quality of motility and sperm morphology. ${ }^{13}$

The main purpose of this study was to examine the large group of the possible predictors of pregnancy through logistic regression analysis. So far, trials have been conducted with single ${ }^{14,15}$ or combinations of a few predictive factors. ${ }^{16,17}$

By a scoring system capable of providing reliable information of IVF/ ICSI outcome in women, the clinician would be able to cater to an individually tailored treatment plan to a patient-couple, who would therefore be well informed about their individual success rate and be able to weigh the benefits, risks and burdens of ART treatment. It would avoid the unnecessary strain over a few patients to undergo a check-cycle of ART, when actually her benefit lies in a donor treatment or other higher alternatives.

The gold standard for outcome measure would be live birth after an ART cycle. This scoring was derived using positive pregnancy as the outcome variable, which indicates its predictive accuracy and clinical value.

\section{STUDY DESIGN}

The study was conducted after receiving institutional review board approval. Patients were provided with counseling, and signed consents were obtained.

A noninterventional, retrospective observational study of 1020 patients was conducted using data from two centers of centre for infertility management and assisted reproduction (CIMAR), unit of Edappal Hospitals Pvt Ltd over 3 years.

Patients involved in this study were registered for IVF/ICSI due to various etiologies and were treated by stimulation protocols specific to their etiologies (e.g. very poor responders underwent prolonged suppression, PCOS/ hyper-responders underwent antagonist protocol); though a majority underwent long protocol stimulation. Initially a smaller study with only long agonist protocol was performed, but the need for an all inclusive study led to expanding the sample size and inclusion of various stimulation protocols. To reflect the broad range of patients typically encountered in clinical practice, no inclusion/exclusion criteria were applied on baseline characteristics.

Analysis was approved and supported by all members of the infertility centers.
On day 2/3 of spontaneous cycle preceding GnRH-analog treatment we obtained:

- Clinical history

- Informed consent

- Serum FSH, LH, E2, P4 values

- Ovarian ultrasonography for number of antral follicles (2-10 $\mathrm{mm})$

- Interpretation of semen quality according to the World Health Organization (WHO) 2010.

All the women were subjected to stimulation, after confirming pituitary desensitization (i.e. no ovarian cysts, endometrial thickness $<5 \mathrm{~mm}$, baseline hormonal assays) and counting the number of antral follicles.

The standard starting dose of gonadotropins was 2 to 6 ampoules, i.e. 150 to $450 \mathrm{IU}$ FSH activity/day; individually tailored based on individual parameters.

On follow-up visits:

- The number of follicles $<10$ to $>21 \mathrm{~mm}$ was noted. Thereafter, transvaginal sonography (TVS) was performed every $2 / 3$ days to evaluate the follicular size, number and quality. The gonadotropin doses were hence adjusted where needed.

- On a true longitudinal view of the uterus, the endometrial thickness was measured as the maximum thickness between the highly reflective interfaces of the endometrial-myometrial junction. The measurement included both the layers of the endometrium. The surrounding low-amplitude echo layer was excluded, because it represents the inner layers of the myometrium. A triple-line pattern was described as hypoechogenic endometrium surrounded by a hyper echogenic zone.

The dose was continued until a response was evident on ultrasound. Dose adjustments were performed according to ovarian follicular response which was monitored by means of TVS and E2 determinations (assayed at the same laboratory). E2 was measured from the morning blood sample on the day of human chorionic gonadotropin (hCG) administration, as a routine protocol $\mathrm{P} 4$ and $\mathrm{LH}$ were also assayed.

When the 2 to 3 largest follicles measured a mean diameter of $\geq 17$ to $18 \mathrm{~mm}, 10,000 \mathrm{IU}$ of hCG (Ovunal SC, Intas Pharmaceuticals, Ahmedabad, India) was administered intramuscularly for the final maturation.

After 36 hours of hCG administration, transvaginal ultrasound guided needle aspiration of follicular fluid was done for oocytes retrieval under short general anesthesia. The number of follicles aspirated and oocytes retrieved was recorded during aspiration. As appropriate ovarian response was defined as retrieval of 4 to 12 oocytes, whereas an inadequate response involved retrieval of three or less oocytes and an excessive response was considered as retrieval of $\geq 13$ oocytes. 
Standard IVF/ICSI procedure was performed.

They were treated with prophylactic oral antibiotics and vaginal progesterone pessaries $200 \mathrm{mg}$ HS (Naturogest/ Susten) from the day of OPU (Ovum Pick Up) till ET (Embryo Transfer).

Fertilization was assessed 16 to 18 hours after injection. Four cell/ 6 to 8 cell on day $2 /$ day 3 respectively with $<20 \%$ fragmentation and equal sized blastomeres were considered as good quality embryos. For all patients 3 to 4 embryos were transferred on day 2/3 with Cook catheter. Surplus good quality embryos were cryopreserved.

They were treated with intramuscular progesterone (100 mg Naturogest/Hald) $100 \mathrm{mg}$ once daily, low molecular weight heparin (Lonopin) $20 \mathrm{mg}$ subcutaneously daily and injection $\mathrm{hCG}$ once in 3 days from the day of ET until serum $\beta$-hCG measurements.

Pregnancy testing by serum $\beta$-hCG was performed on day 14 post ET. A positive pregnancy test (serum $\beta$-hCG value $\geq 50 \mathrm{IU} / \mathrm{ml}$ ) was followed by a USG 4 weeks later to confirm intrauterine pregnancy and number of gestational sacs. Clinical pregnancies were defined by the presence of cardiac activity at 6 to 7 weeks scan; miscarriages by histological confirmation of gestational products and no ultrasound detectable pregnancy with a falling $\beta$-hCG value; chemical pregnancy by $\beta-\mathrm{hCG}>50 \mathrm{IU} / \mathrm{ml}$; and ongoing pregnancies beyond 10 to 12 weeks of gestation which were referred to fetomaternal unit for antenatal care.

IVF was done in 12 patients in this study: 10 were $\beta$-hCG negative, 1 was $\beta$-hCG positive and 1 had history of empty follicle syndrome in previous stimulation cycle.

The primary objective of this study was to examine the large groups of possible predictors of pregnancy through logistic regression analysis. Secondary objective was to establish a scoring system using these predictors such that a statistically driven success rate could be arrived at.

The primary outcome measure (end point) in this study was ovarian response [follicles $>12 \mathrm{~mm}$ on day of $\mathrm{hCG}$ and the number of M2 oocytes retrieved on obum pick up (OPU)] and secondary outcome measure was clinical pregnancy obtained.

\section{HORMONAL ASSAYS}

Serum E2, P4, follicle stimulating hormone (FSH) and luteinizing hormone (LH) was measured by Elecsys kit using the principles of electrochemiluminescence (Elecsys and Cobase analysers, Roche diagnostics, USA, Indiana Polis, made in Germany). The sensitivity of E2 was $5 \mathrm{pg} / \mathrm{ml}$, FSH and LH was $0.1 \mathrm{mIU} / \mathrm{ml}$. Serum progesterone had a sensitivity of $0.035 \mathrm{ng} / \mathrm{ml}$. This assay was used for the duration of the study. Besides the internal quality control checks performed daily by the institution laboratory, the assays were calibrated whenever a new reactive batch was used or whenever an outcome outside the normal range was observed. Furthermore, external quality control assessment of every hormone assay was performed monthly by chemiluminescence.

\section{STATISTICAL ANALYSIS}

Descriptive and inferential statistical analysis has been carried out in the present study. Results on continuous measurements are presented on mean $\pm \mathrm{SD}$ (min-max) and results on categorical measurements are presented in number (\%). Significance so assessed at $5 \%$ level of significance. The following assumptions on data are made:

1. Dependant variables should be normally distributed

2. Samples drawn from the population should be random. Cases of the samples should be independent.

Chi-square/Fisher exact test has been used to find the significance of study parameters on categorical scale between two or more groups. Sample size (whole table) - a sufficiently large sample size is assumed. If the Chi-square test is conducted on a sample with a smaller size, then the Chi-square test will yield an inaccurate inference. The researcher, by using Chi-square test on small samples, might end up committing a type II error. Some require ${ }^{5}$ or more, and others require 10 or more. A common rule, of 5 or more in all cells of a $2 \times 2$ table, and 5 or more in $80 \%$ of cells in larger tables, but no cells with zero expected count. When this assumption is not met, Fisher exact test or Yates' correction is applied. Then the calculation of the conditional probability of getting the actual matrix is given by a multivariate generalization of the hyper geometric probability function.

Multiple logistic regressions were used to find out the individual risk factors. Using the adjusted odd ratio, we scored the risk factors.

- ${ }^{+}$Suggestive significance (p-value: $0.05<\mathrm{p}<0.10$ )

- Moderately significant ( $p$-value: $0.01<p \leq 0.05$ )

_ **Strongly significant ( $\mathrm{p}$-value: $\mathrm{p} \leq 0.01$ )

Statistical software: The statistical software namely SAS 9.2, SPSS 15.0, Stata 10.1, Med Calc 9.0.1, Systat 12.0 and $\mathrm{R}$ environment ver.2.11.1 were used for the analysis of the data and Microsoft Word and Excel have been used to generate Graphs 1 to 29 and Tables 1 to 3 .

\section{RESULTS}

One thousand and twenty patients were enrolled in this study without an inclusion/exclusion criteria. They underwent various stimulation protocols. The data were retrospectively analyzed statistically to arrive at a clinically applicable scoring.

The distribution of patients according to different factors is given in Tables 1 to 3. Women's age ranged from 21 to 40 years with a mean age of 32.18 years and mean duration of infertility of 6.56 years. 
The mean basal antral follicle count (AFC) was 11.4 and the mean endometrial thickness on day of human chrionic gonadotropin (hCG) was $9.28 \mathrm{~mm}$. The basal follicle stinulating hormone (FSH) was $5.4 \mathrm{mIU} / \mathrm{ml}$ and basal E2 was $43.2 \mathrm{pg} / \mathrm{ml}$; while on the day of hCG was $2369 \mathrm{mIU} /$ $\mathrm{ml}$. The most common indication for ART was male factor infertility $36.3 \%$.

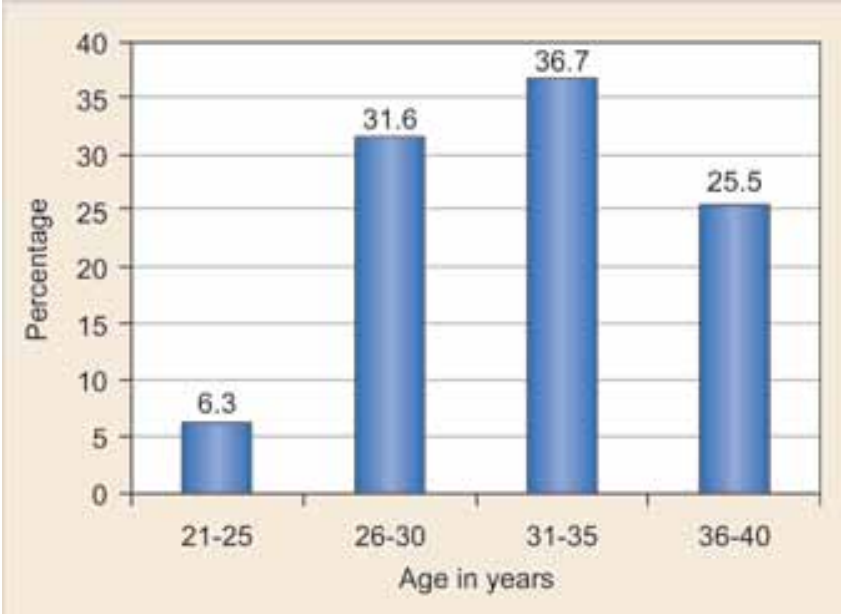

Graph 1: Age distribution

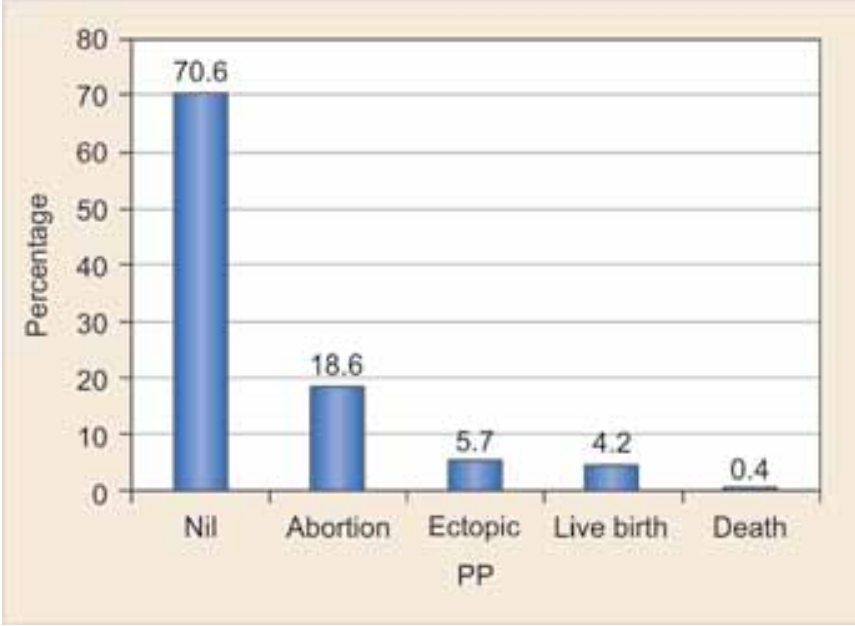

Graph 3: Previous pregnancy

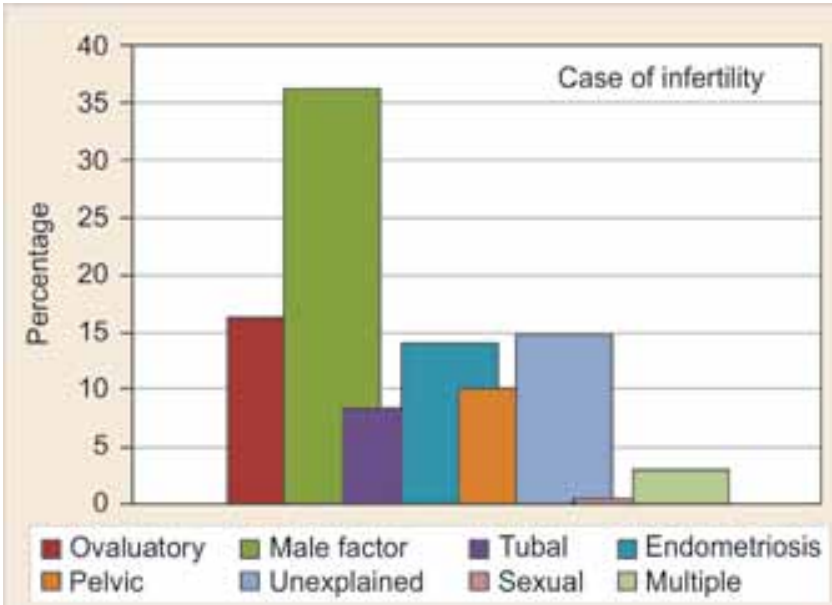

Graph 5: Cause of infertility
An average of 9.44 MII oocytes was obtained. The overall fertilization rate of confirmed metaphase II oocytes was 8 per cycle with a mean number of three embryos being cryopreserved.

In 978 (95.9\%) women embryo transfer was done. Fourty-two (4.1\%) cycles were cancelled, of these: 3 due to empty follicle syndrome (1 IVF + 2 ICSI), 12 severe ovarian

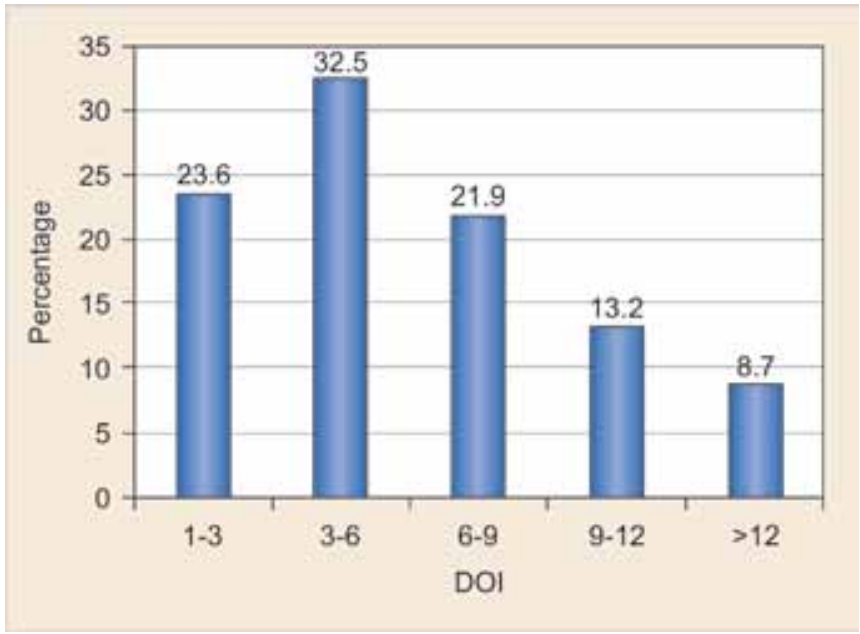

Graph 2: Duration of infertility

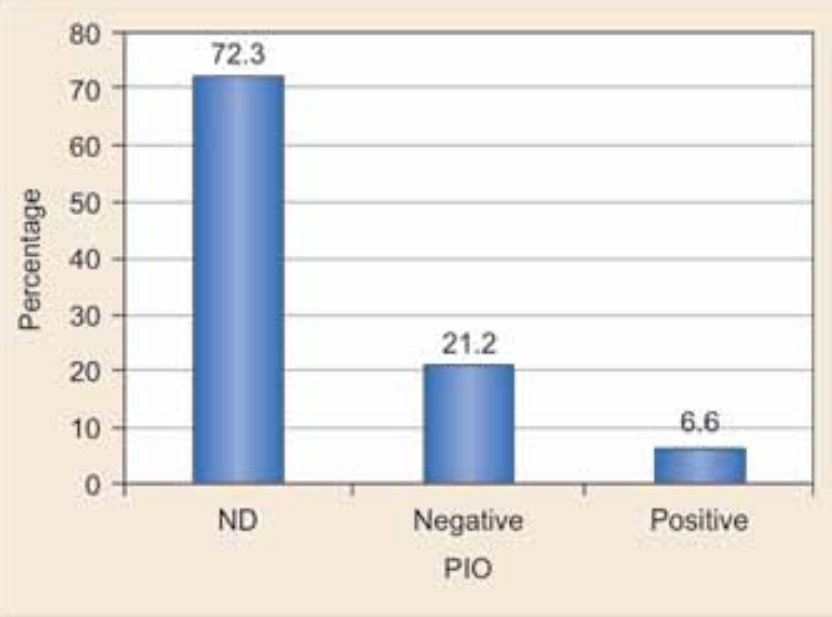

Graph 4: Previous IVF outcome

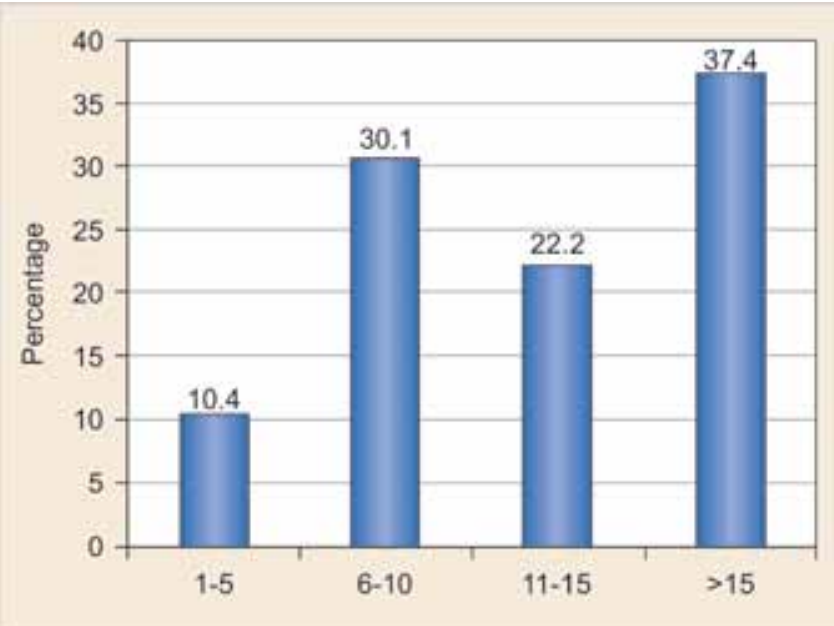

Graph 6: Antral follicle count 
hyperstimulation syndrome (OHSS), in 2 no sperms were obtained, 1 was diagnosed endometrial cancer during the ICSI treatment course and 1 cycle was deferred due to severe abdominal pain due to acute gastro enteritis.

Other cases involved in this study were: 6 CBAVD $(2$ were $\beta$-hCG negative and 4 positive $\beta$-hCG); 3 MRKH (negative $\beta$-hCG); 4 patients with hypogonadotropic hypo-

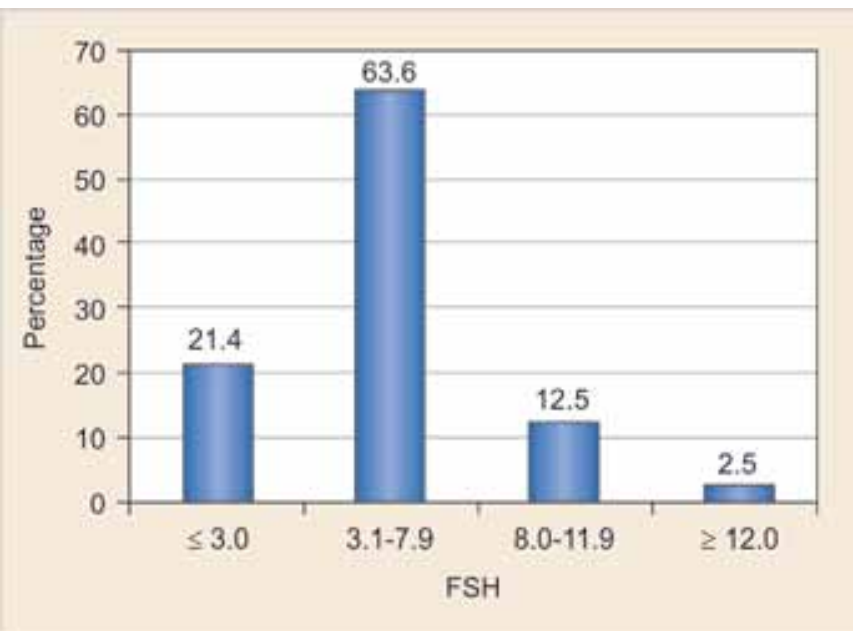

Graph 7: Day 2/3 FSH

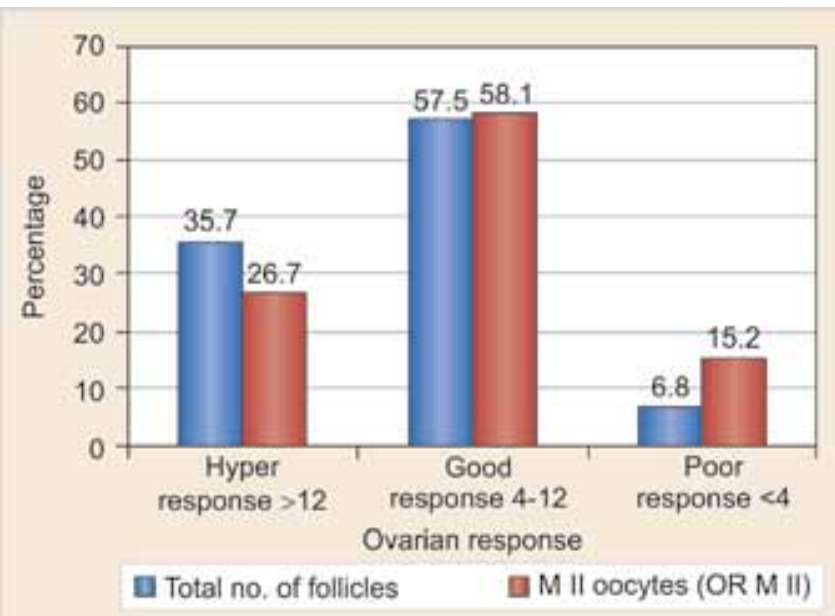

Graph 9: Ovarian response: number of follicles on d-hCG and number of MII retrieved

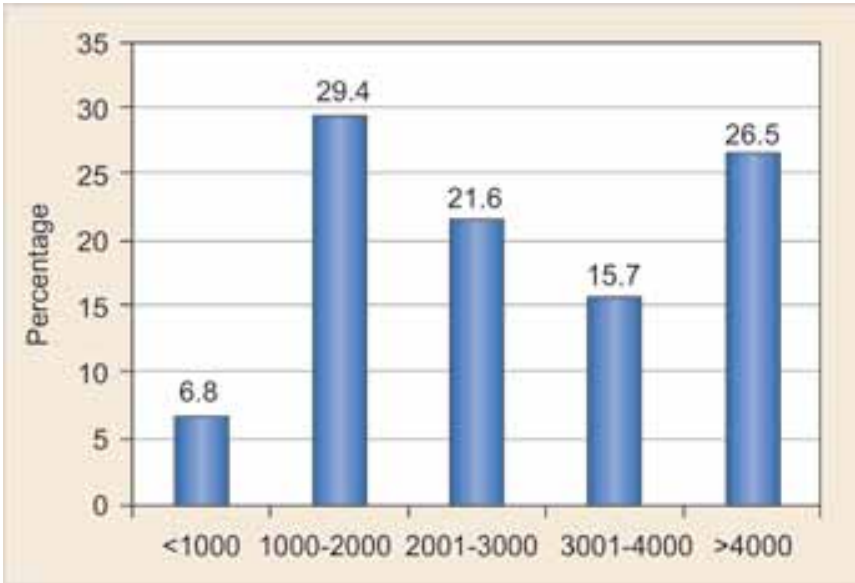

Graph 11: Estradiol on day of human chorionic gonadotropin gonadism ( 3 negative $\beta$-hCG 1 positive $\beta$-hCG); 1 patient with husband having vasal aplasia ( $\beta$-hCG negative) and 1 patient post-tubal ligation ( $\beta$-hCG positive).

Pregnancy outcomes for the 1020 participants; the distribution and correlation of various predictive factors under study with ART outcome are summarized in Charts 1 to 13 .

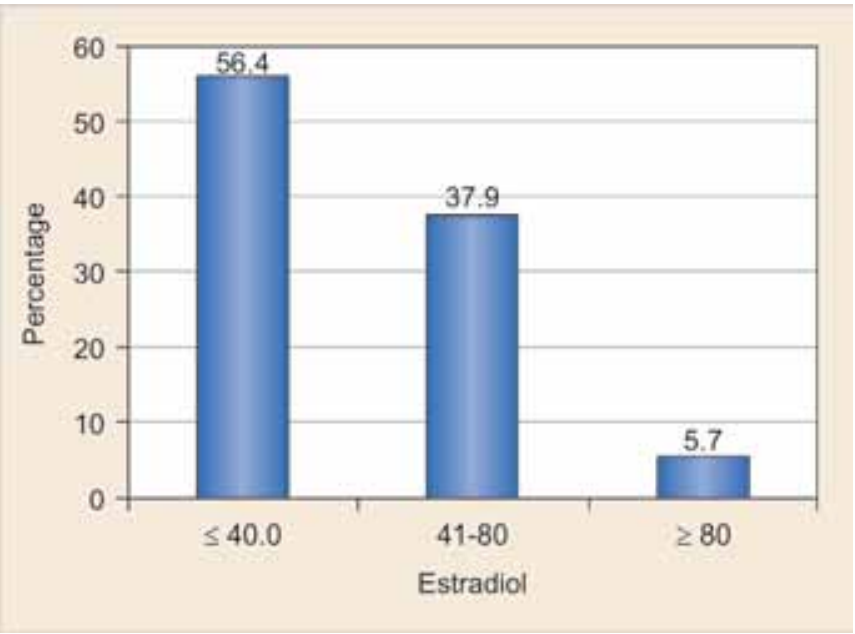

Graph 8: Day 2/3 estradiol

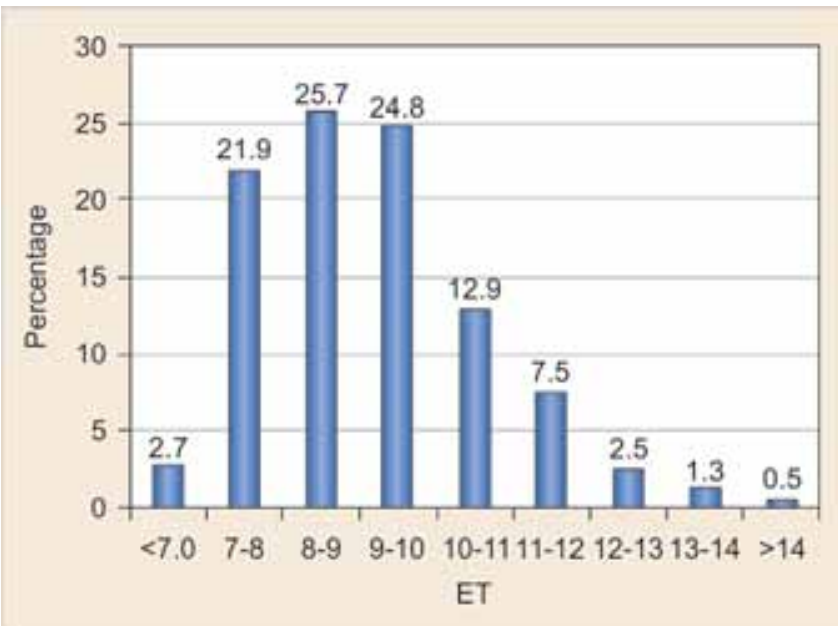

Graph 10: Endometrial thickness on day of hCG trigger

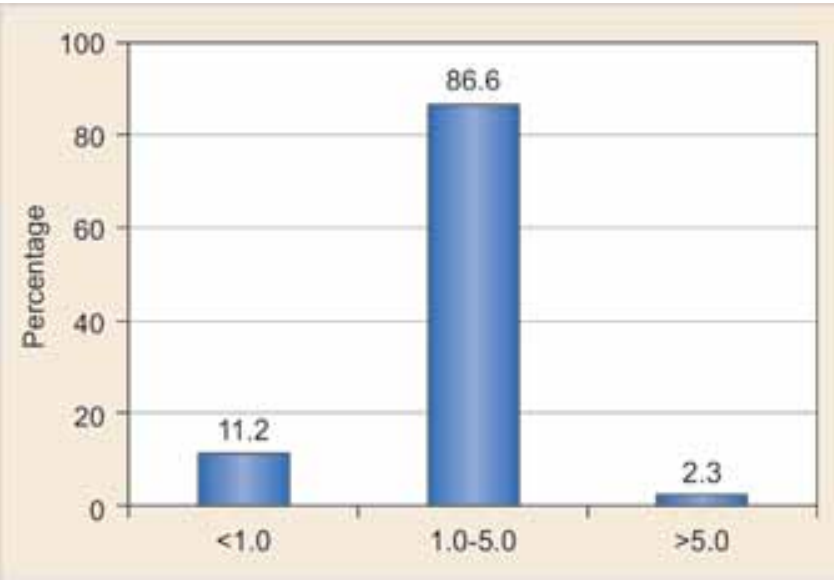

Graph 12: Luteinizing hormone on day of human chorionic gonadotropin 
Chemical, clinical and ongoing pregnancy rates per initiated cycle were $38.1,28.3$ and $24.5 \%$ respectively.

Seventeen pregnancies failed at biochemical stage.

$1.2 \%$ of women were hospitalized due to severe OHSS.

Women with age $\leq 25$ years $(6.3 \%)$, basal FSH $<8 \mathrm{mIU} / \mathrm{ml}$ $(85 \%)$, serum E2 $2000-3000 \mathrm{pg} / \mathrm{ml}(21.6 \%)$ and hyper ovarian response according to number of MII oocytes

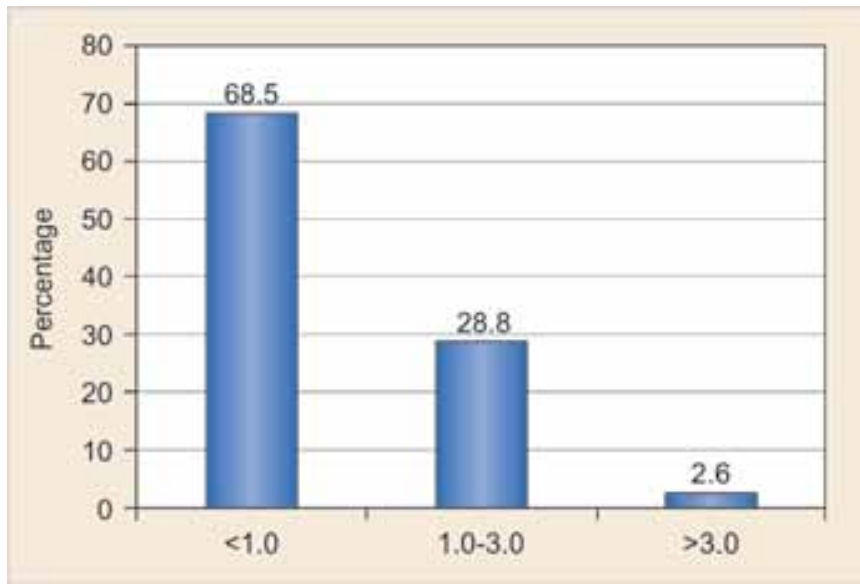

Graph 13: Progesterone on day of human chorionic gonadotropin

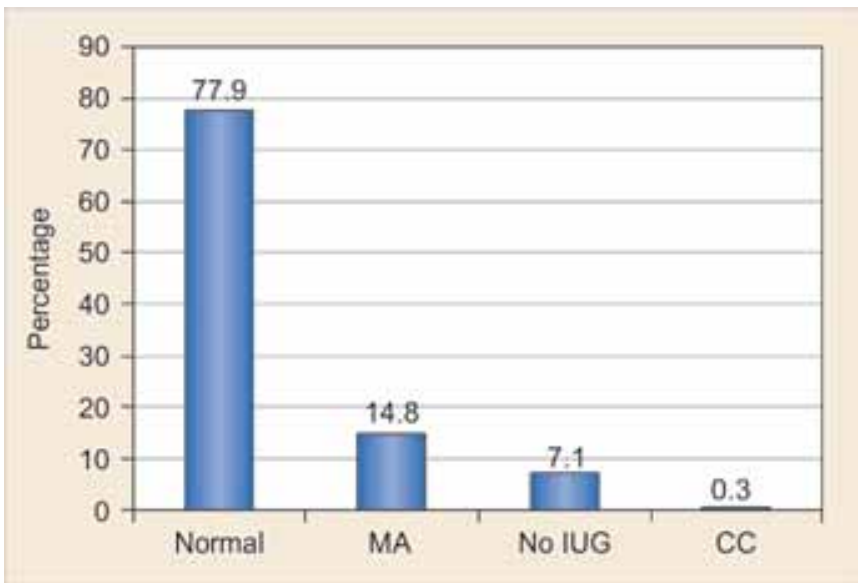

Graph 15: Six weeks of follow-up

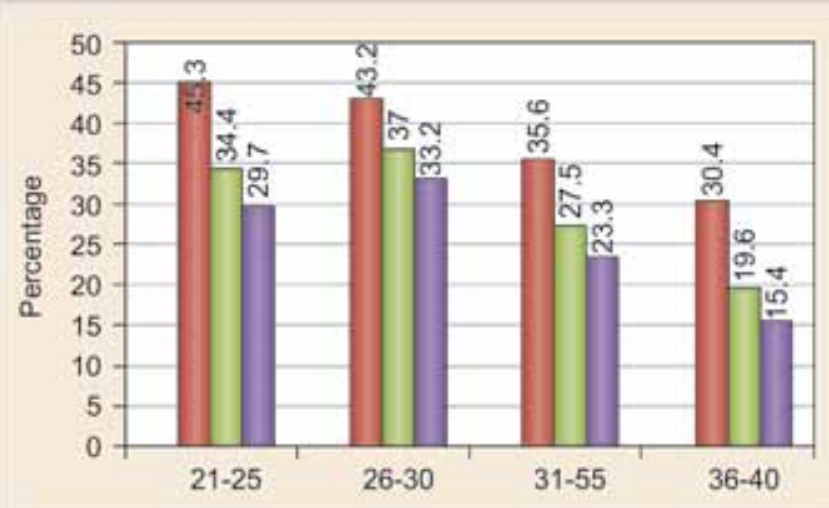

Pregnancy positive $\square$ Clinical preg. (+ve at 6 weeks) 0 OP

Graph 17: Age in years—correlation with pregnancy outcome retrieved $(26.7 \%)$ had statistically significant $(\mathrm{p}<0.05)$ higher pregnancy rate.

Pregnancy rate was toward increasing trend in women with $<6$ years duration of infertility $(56.1 \%)$, basal $\mathrm{AFC} \geq 11(40.5 \%)$, basal E2 40 to $80 \mathrm{pg} / \mathrm{ml}$ (37.9\%), P4 $<1.0 \mathrm{ng} / \mathrm{ml}(68.5 \%)$ and endometrial thickness of 7 to 12 $\mathrm{mm}(82.8 \%)$.

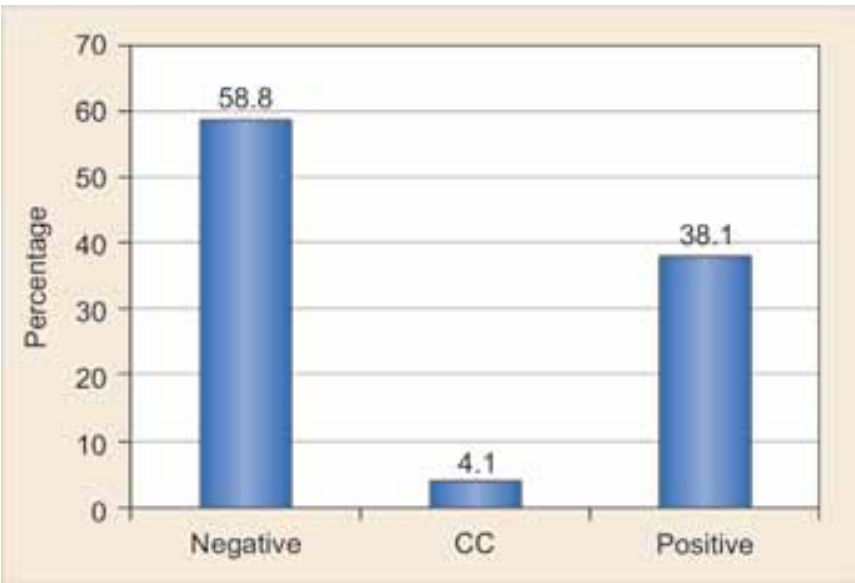

Graph 14: Pregnancy outcome

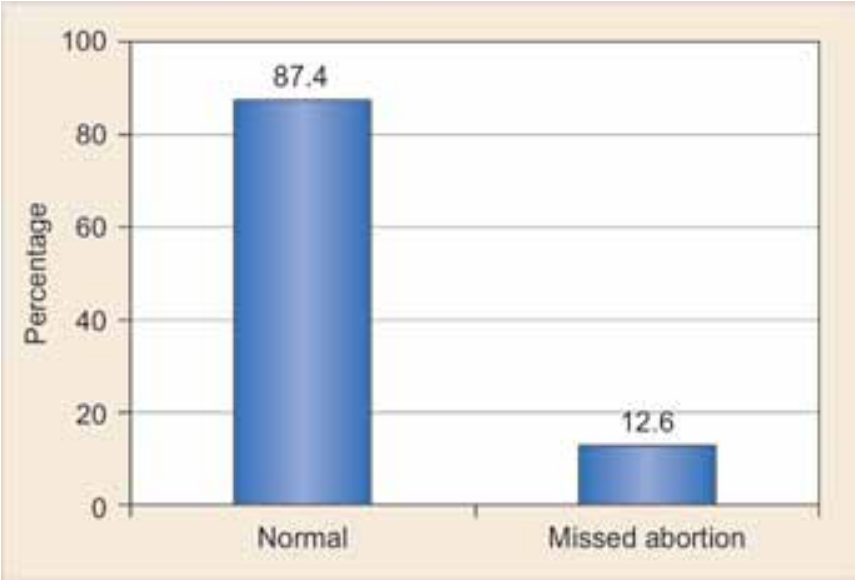

Graph 16: Ongoing pregnancy

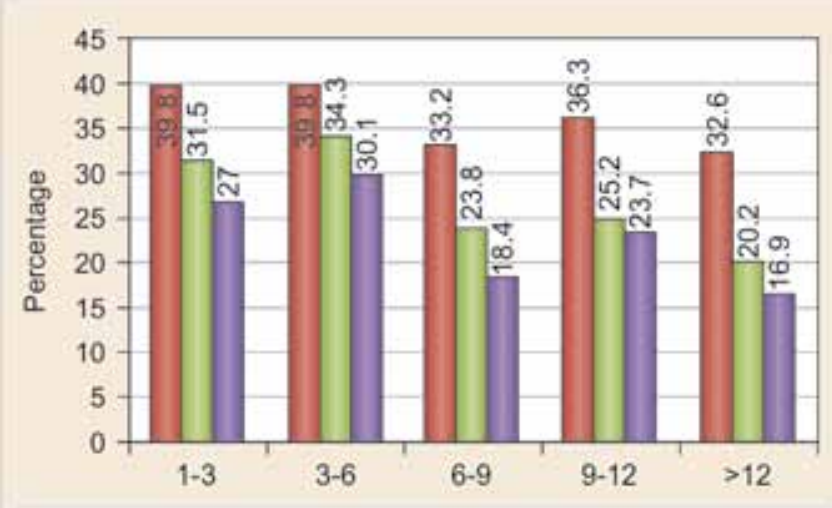

D Pregnancy positive $\square$ Clinical preg. (+ve at 6 weeks) $\square$ OP

Graph 18: Duration of intertility-correlation with pregnancy outcome 
The pregnancy rate among those who had no previous pregnancy $(37.6 \%)$ or had previous miscarriage $(39.5 \%)$ was similar. Those who had first cycle of ART had higher pregnancy rate (39.3\%). P4 level was increased in $31.4 \%$ of patients, 587 women $(57.5 \%)$ had good ovarian response, i.e. had between 4 and 12 follicles of $>12 \mathrm{~mm}$ mean diameter and 593(58.1\%) had 4 to 12 MII oocytes.

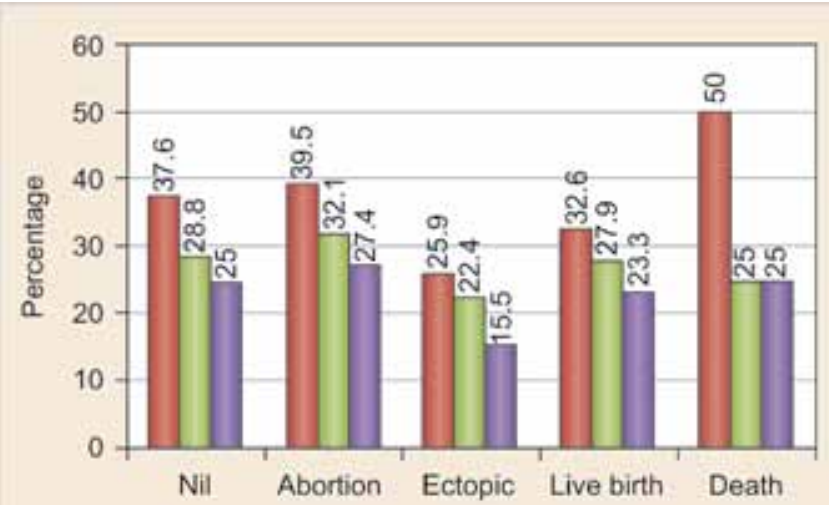

Pregnancy positive $\square$ Clinical preg. (+ve at 6 weeks) $\square$ OP

Graph 19: Previous pregnancy outcome-correlation with pregnancy outcome

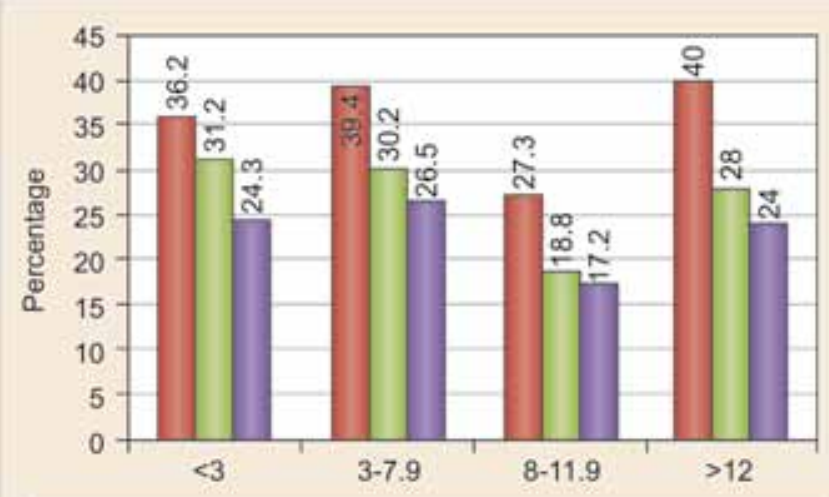

Pregnancy positive $\square$ Clinical preg. (+ve at 6 weeks) $\mathbf{D O P}$

Graph 21: Basal FSH—correlation with pregnancy outcome

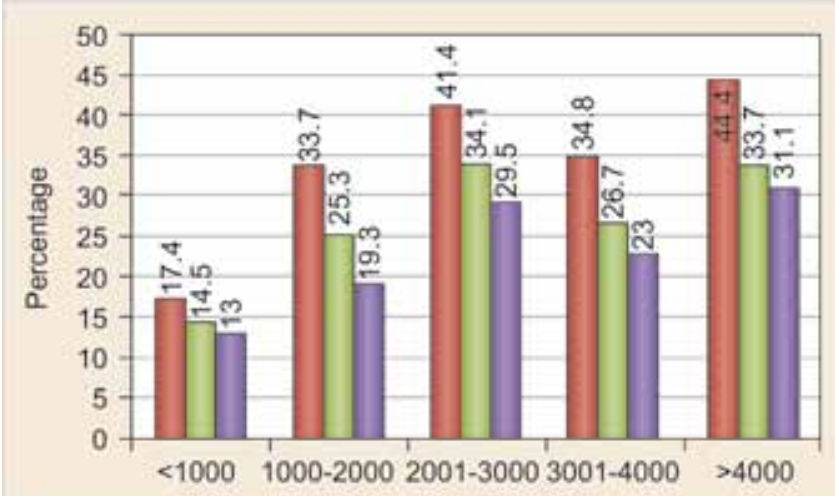

Pregnancy positive $\square$ Clinical preg. (+ve at 6 weeks) $\square$ OP

Graph 23: E2 on D-hCG—correlation with pregnancy outcome
Fourteen predictor variables were entered into a multivariate logistic regression model with the dependant variable being the pregnancy. The multiple regression analyses results showed that the occurrence of pregnancy (positive predictor) was significantly predicted by age $<25$ years, duration of infertility of $<6$ years, basal serum FSH 3-7.9 mIU/ml and serum E2 on day of hCG 2000-3000 pg/ml. Age $>35$

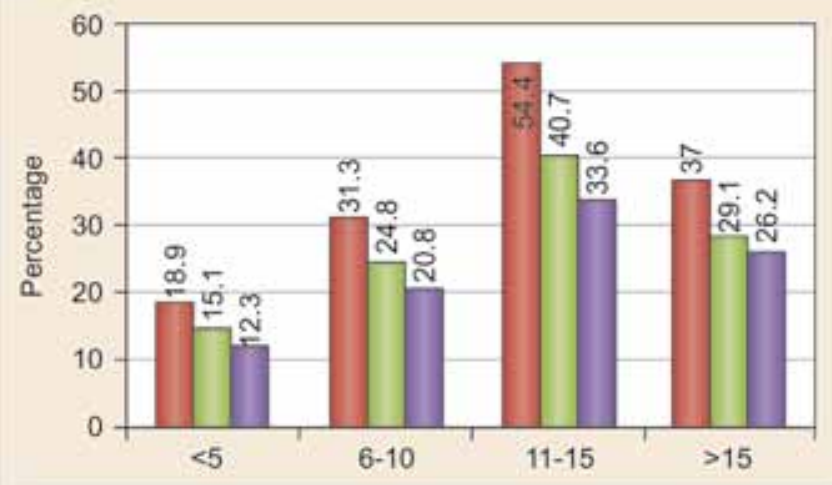

Pregnancy positive $\square$ Clinical preg. (+ve at 6 weeks) DOP

Graph 20: Basal total AFC—correlation with pregnancy outcome

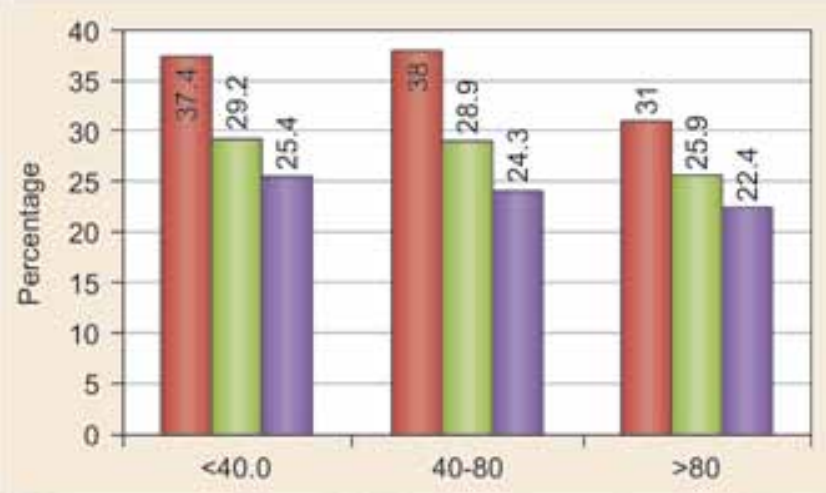

Pregnancy positive $\square$ Clinical preg. (+ve at 6 weeks)

Graph 22: Basal E2—correlation with pregnancy outcome

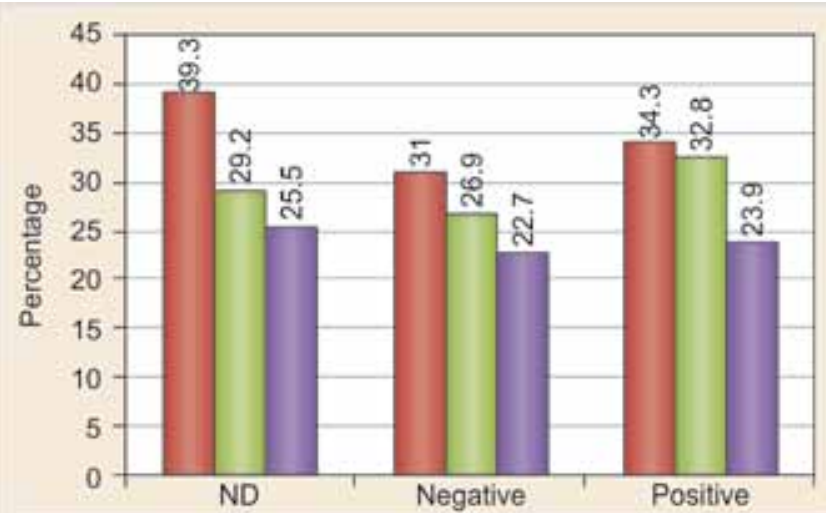

Pregnancy positive $\square$ Clinical preg. (+ve at 6 weeks)

Graph 24: Previous IVF outcome-correlation with pregnancy outcome 


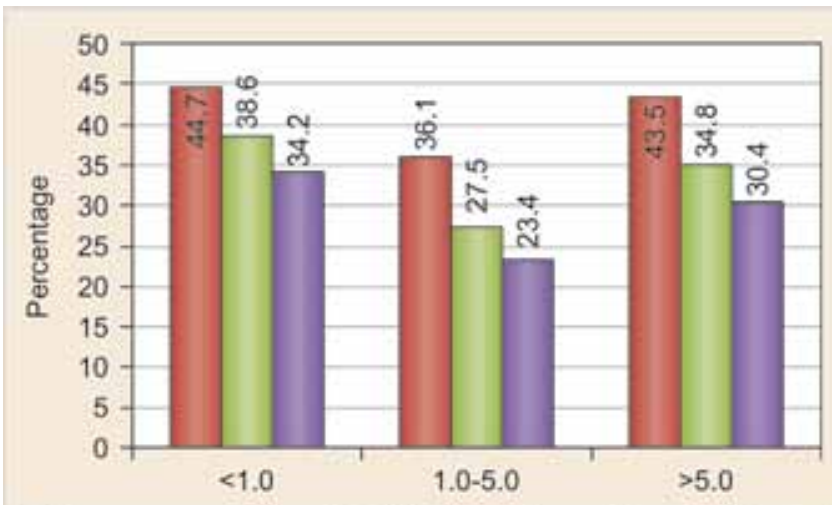

Pregnancy positive $\square$ Clinical preg. (+ve at 6 weeks) $\square$ OP

Graph 25: LH on day of hCG-correlation with pregnancy outcome

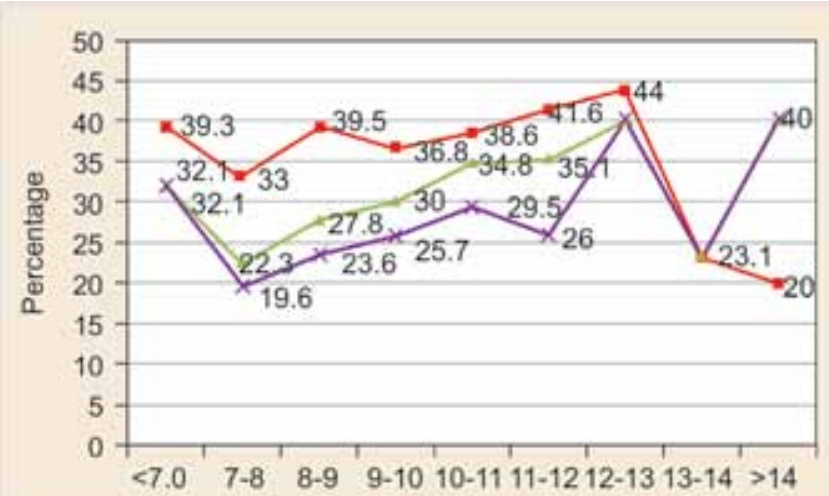

Pregnancy positive $=$ - Clinical preg. (+ve at 6 weeks) $*$ OP

Graph 27: Endometrial thickness-correlation with pregnancy outcome

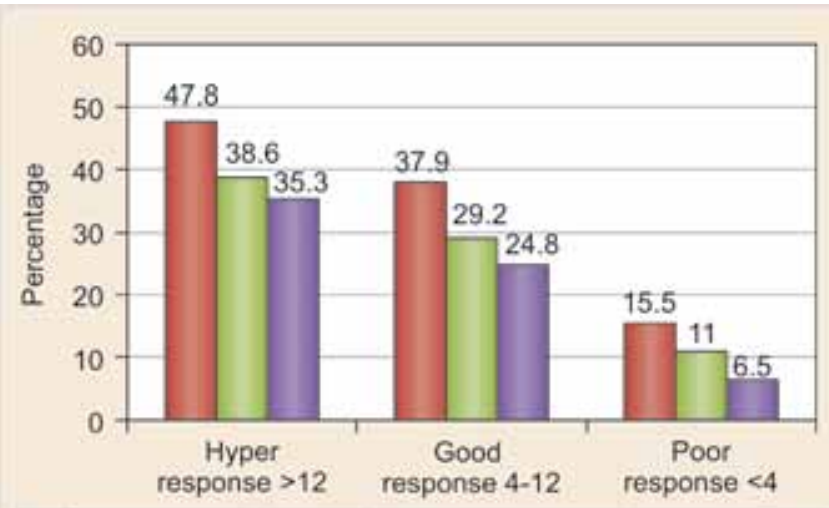

Pregnancy positive $\square$ Clinical preg. (+ve at 6 weeks) $\square$ OP

Graph 29: Ovarian response-correlation with pregnancy outcome

years, basal serum FSH $>8 \mathrm{mIU} / \mathrm{ml}$ and $<4$ MII oocytes are significant negative predictors (Tables 1 to 3 ).

The modified scoring by changing few scores according to clinical relevance is given in Table 2 .

The statistical scoring to predict the chance of pregnancy using 14 factors is given in Table 3.

The cut off score is 43 for positive pregnancy outcome of at least $50 \%$ chance.

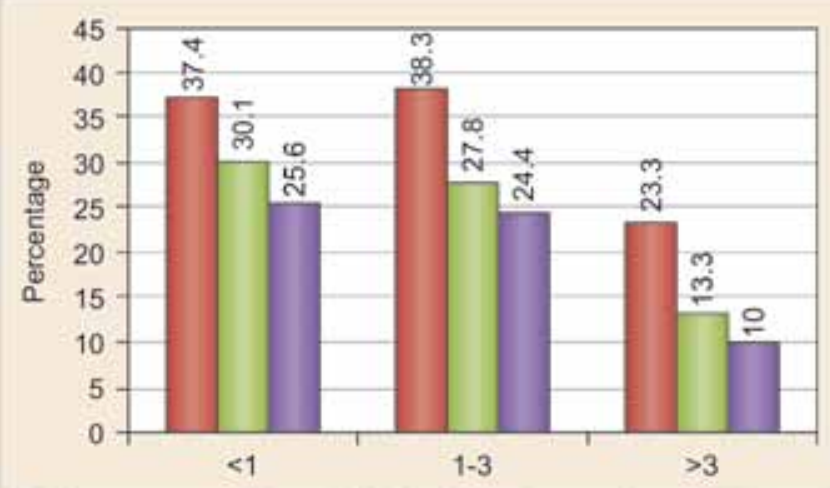

Pregnancy positive $\square$ Clinical preg. (+ve at 6 weeks) $\square$ OP

Graph 26: P4 on day of hCG—correlation with pregnancy outcome

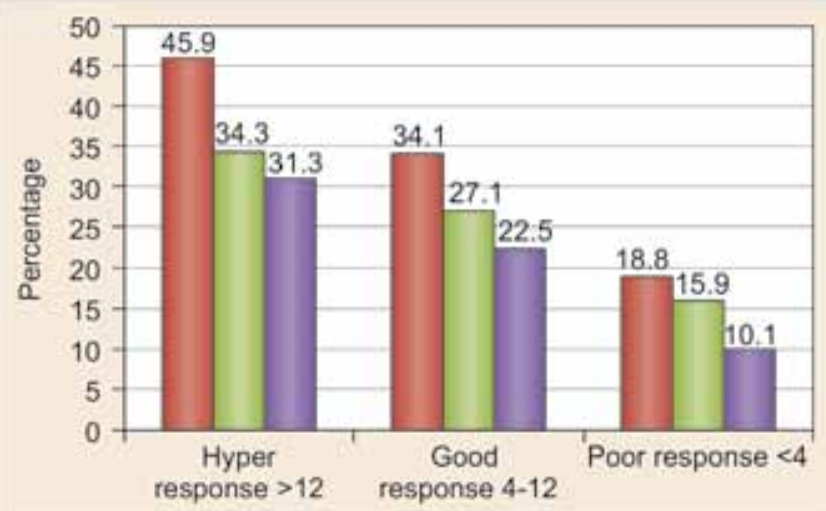

Pregnancy positive $\square$ Clinical preg. (+ve at 6 weeks) $\square$ OP

Graph 28: Ovarian response-correlation with pregnancy outcome

\section{DISCUSSION}

Age was an independent predictor of pregnancy in this study in contrast to study by Todorovic et al. ${ }^{22}$ Spandorfer et al previously demonstrated that maternal age is the predictor of first choice for ovarian reserve testing determining over $80 \%$ success rates after any fertility treatment/ART. ${ }^{20,21}$

The loss of fecundity with age appears to be a consequence of both oocyte depletion and reduced oocyte quality. Young women with limited reserve can have good success because of high quality of eggs (quality matters more than quantity). In this study, ongoing pregnancy rate was $6.8 \%$ in poor responders $(<4$ oocytes) compared to $\%$ reported by National Summary and Fertility Clinic Reports 2009 (one woman among 16, conceived at 26 years even with poor ovarian reserve). So, diminished reserve should not be used as exclusion criteria in young women, though their cancelation rates are increased, still they have satisfactory pregnancy rates.

After 34 years chance of producing live births decreases steadily and will be under $10 \%$ per cycle in women $>40$ years (CDC report 2003). The reduced live birth rate seen in older 
women is also a result of the increased incidence of miscarriages. In this study, $19.6 \%$ women $>35$ years continued to a clinical pregnancy as compared to $33 \%$ in women $<35$ years. Van Voorhis et al reported pregnancy losses of $34.5 \%$ by 43 years. ${ }^{26}$ Spandorfer et al also clearly demonstrated a linear increase in miscarriage rates with advancing maternal age. $^{27}$

The reduced fertility associated with aging is primarily associated with aging of ovaries and oocytes, rather than that of the uterus and endometrium. Aging is associated with progressive follicular depletion and diminished oocyte quality, and in turn reduction in the size and the cohort of follicles available to respond to gonadotropin stimulation. ${ }^{4}$ This was underscored by the observation that donor oocyte cycles resulted in high pregnancy rates among recipient women, irrespective of their age. ${ }^{26}$

The ongoing pregnancy rate in this study showed a decreasing trend with increasing duration of infertility divided into five groups (Graph 1). There was no statistical difference in positive pregnancies between 1 and 3 years $(39.8 \%)$ and 3 to 6 years $(39.8 \%)$. But the difference was significant in women with $<6$ years $(39.8 \%)$ ( $p$-value 0.335$)$ and $>6$ years $(34 \%)$ duration of infertility. A similar analysis if HEFA data base demonstrated that even after adjustment for age, there was a significant decrease in live birth rate in ART, with increasing duration of infertility from 1 to 12 years $(\mathrm{p}<0)$.

After $28.9 \%$ of the cycles in this study were in women with one or more previous pregnancies that had ended in miscarriage, ectopic pregnancy or live birth compared to $27 \%$ as reported by National Summary and Fertility Clinics Reports 2009. These pregnancies were the result of ART or were conceived naturally. In all age groups, women who had a previous miscarriage, ectopic pregnancy or live birth were about as likely to have a pregnancy as women who had never been pregnant. Thus, a history of unsuccessful pregnancy does not appear to be associated with lower chances for success using ART. ${ }^{37}$

According to National Summary and Fertility Clinic Reports in $45 \%$ of ART cycles that used fresh nondonor eggs or embryos in 2009 previous ART cycles had been performed compared to $28 \%$ in this study. Percentages of ART cycles that resulted in pregnancy were same for women who had previously undergone an ART cycle ending in abortion or no pregnancy. It was found that, percentages of ART cycles that resulted is pregnancy among women who did not undergo a

Table 1: Logistic regression analysis to predict the positive pregnancy

\begin{tabular}{llllll}
\hline Variables & Logit coefficient & Se & $p$-value & Adj OR & Score \\
\hline Age $\leq 25$ & 0.269 & 0.284 & 0.344 & 1.308 & 5 \\
DOI $\leq 3$ & 0.138 & 0.166 & 0.406 & 1.148 & 4 \\
Prev LB & -0.397 & 0.362 & 0.272 & 0.672 & 2 \\
Prev P-MA & -0.118 & 0.279 & 0.671 & 0.888 & 3 \\
O & 0.329 & 0.211 & 0.119 & 1.390 & 5 \\
Hyper response: Follicles & 0.517 & 0.144 & 0.000 & 1.676 & 6 \\
Hyper response: M II & 0.236 & 0.145 & 0.105 & 1.266 & 5 \\
AFC (11-15) & 0.343 & 0.149 & 0.021 & 1.409 & 5 \\
FSH <8 & 0.220 & 0.199 & 0.269 & 1.246 & 4 \\
P4 on hCG: $<1.0$ & 0.075 & 0.147 & 0.610 & 1.078 & 4 \\
E2 2000-3000 & 0.218 & 0.161 & 0.177 & 1.244 & 4 \\
ET (7-12) & -0.060 & 0.267 & 0.822 & 0.942 & 3 \\
\hline
\end{tabular}

Table 2: Modified logistic regression analysis to predict the positive pregnancy

\begin{tabular}{llllll}
\hline Variables & Logit coefficient & Se & $p$-value & Adj OR & Score \\
\hline Age $\leq 25$ & 0.182 & 0.278 & 0.514 & 1.199 & 4 \\
DOI $\leq 6$ & 0.136 & 0.141 & 0.335 & 1.146 & 1.105 \\
Prev no any preg & 0.100 & 0.152 & 0.508 & 1.276 & 4 \\
Prev IVF-ND & 0.244 & 0.159 & 0.125 & 1.415 & 5 \\
O & 0.347 & 0.207 & 0.093 & 1.043 & 4 \\
Basal E2 40-80 & 0.042 & 0.140 & 0.763 & 1.561 & 6 \\
Basal AFC $\geq 11$ & 0.446 & 0.154 & 0.004 & 1.054 & 4 \\
Basal FSH 3-7.9 & 0.053 & 0.144 & 0.714 & 1.206 & 4 \\
E2 on hCG 2000-3000 & 0.188 & 0.162 & 0.247 & 1.043 & 4 \\
P4 on hCG <1.0 & 0.042 & 0.147 & 0.773 & 0.958 & 3 \\
ET on hCG 7-12 & -0.043 & 0.267 & 0.873 & 1.571 & 6 \\
$>4$ (ORF) & 0.452 & 0.271 & 0.095 & 0.237 & 1.213 \\
>4 M II & 0.193 & 0.164 & &
\end{tabular}


Table 3: Statistical scoring for predicting outcome

\begin{tabular}{|c|c|c|c|c|c|}
\hline Variables & Logit coefficient & $\mathrm{Se}$ & $p$-value & Adj OR & Score \\
\hline \multicolumn{6}{|l|}{ Age in years } \\
\hline $21-25$ & 0.041 & 0.196 & 0.836 & 1.041 & 4.0 \\
\hline $26-30$ & 0.192 & 0.213 & 0.368 & 1.212 & 4.0 \\
\hline $31-35$ & 0.241 & 0.335 & 0.472 & 1.272 & 5.0 \\
\hline $36-40$ & - & - & - & - & 0.0 \\
\hline \multicolumn{6}{|l|}{ Duration years } \\
\hline$<6$ & -0.176 & 0.238 & 0.460 & 0.839 & 3.0 \\
\hline $6-12$ & 0.154 & 0.246 & 0.532 & 1.166 & 4.0 \\
\hline$>12$ & - & - & - & - & 0.0 \\
\hline \multicolumn{6}{|l|}{ Previous pregnancy } \\
\hline Nil & - & - & - & - & 0.0 \\
\hline Live birth & -0.326 & 0.367 & 0.375 & 0.722 & 3.0 \\
\hline \multicolumn{6}{|l|}{ Previous outcome } \\
\hline Negative & - & - & - & - & 0.0 \\
\hline Positive-abortion & -0.093 & 0.282 & 0.741 & 0.911 & 3.0 \\
\hline \multicolumn{6}{|l|}{ Cause of infertility } \\
\hline PCOD ovulatory & 0.568 & 0.269 & 0.035 & 1.765 & 7.0 \\
\hline Male factor & 0.249 & 0.217 & 0.251 & 1.282 & 5.0 \\
\hline Endometriosis-E/tuboperitoneal & 0.239 & 0.228 & 0.296 & 1.269 & 5.0 \\
\hline Unexplained & 0.468 & 0.249 & 0.060 & 1.596 & 6.0 \\
\hline \multicolumn{6}{|l|}{ Total number of follicles } \\
\hline Good response & 0.404 & 0.280 & 0.149 & 1.498 & 5.0 \\
\hline Poor response/hyper response & - & - & - & - & 0.0 \\
\hline \multicolumn{6}{|l|}{ M2 oocytes } \\
\hline Good response & 0.188 & 0.165 & 0.255 & 1.207 & 4.0 \\
\hline Poor response/hyper response & - & - & - & - & 0.0 \\
\hline \multicolumn{6}{|l|}{ Total basal AFC } \\
\hline$<5$ & - & - & - & - & 0.0 \\
\hline$>5$ & 0.648 & 0.294 & 0.028 & 1.911 & 7.0 \\
\hline \multicolumn{6}{|l|}{ Basal FSH $\mathrm{mlU} / \mathrm{ml}$} \\
\hline$<8$ & - & - & - & - & 0.0 \\
\hline$>8$ & -0.182 & 0.206 & 0.377 & 0.833 & 3.0 \\
\hline \multicolumn{6}{|l|}{ Basal E2 Pg/ml } \\
\hline$<40$ or $>80$ & - & - & - & - & 0.0 \\
\hline $40-80$ & 0.068 & 0.142 & 0.632 & 1.070 & 4.0 \\
\hline \multicolumn{6}{|l|}{ E2 on $h C G$} \\
\hline$<1000$ or $>4000$ & - & - & - & - & 0.0 \\
\hline $1000-4000$ & -0.240 & 0.150 & 0.110 & 0.787 & 3.0 \\
\hline \multicolumn{6}{|l|}{ LH on hCG } \\
\hline$<1.0$ or $>5.0$ & - & - & - & - & 0.0 \\
\hline $1-5$ & -0.354 & 0.201 & 0.079 & 0.702 & 2.0 \\
\hline \multicolumn{6}{|l|}{ P4 on $h C G$} \\
\hline$<1.0$ & 0.093 & 0.153 & 0.540 & 1.098 & 4.0 \\
\hline$>1.0$ & - & - & - & - & 0.0 \\
\hline \multicolumn{6}{|l|}{ Endometrial thickness } \\
\hline$<7$ or $>12$ & - & - & - & - & 0.0 \\
\hline $7-12$ & -0.089 & 0.275 & 0.745 & 0.915 & 3.0 \\
\hline
\end{tabular}

Cut off score is $\geq 43$ for positive outcome on at least $50 \%$ of chance

previous ART cycles, comparable to study by Croucher et $\mathrm{al}^{36}$ and National Summary and Fertility Clinic Reports. ${ }^{37}$ Croucher et al concluded biochemical and failed clinical pregnancy should be viewed with a degree of cautious optimism.

Basal FSH level of about $12 \mathrm{mIU} / \mathrm{ml}$ is correlated with a very low chance of pregnancy. ${ }^{18}$ In the present study, basal FSH was one of the statistically significant predictor of pregnancy in multivariate logistic regression analysis. Majority of pregnancies occurred in woman with basal FSH $<7.9 \mathrm{mIU} / \mathrm{ml}$. Results were similar to a recent retrospective analysis by Roberts et $\mathrm{al}^{23}$ who showed, that elevated basal FSH levels predicts a poor response has been reported. The specificity decrease and sensitivity increase with decreasing 


\section{CLINICAL CORRELATION}

\section{Chart 1}

\begin{tabular}{lllll}
\hline Age in years & Number of patients & Pregnancy positive & Clinical preg. (+ve at 6 weeks) & OP \\
\hline $21-25$ & $64(6.3 \%)$ & $29(45.3 \%)$ & $22(34.4 \%)$ & $19(29.7 \%)$ \\
$26-30$ & $322(31.6 \%)$ & $139(43.2 \%)$ & $119(37 \%)$ & $107(33.2 \%)$ \\
$31-35$ & $374(36.7 \%)$ & $133(35.6 \%)$ & $103(27.5 \%)$ & $87(23.3 \%)$ \\
$36-40$ & $260(25.5 \%)$ & $79(30.4 \%)$ & $51(19.6 \%)$ & $40(15.4 \%)$ \\
\hline Total & $1020(100 \%)$ & $380(100 \%)$ & $295(100 \%)$ & $253(100 \%)$ \\
\hline
\end{tabular}

Chart 2

\begin{tabular}{lllll}
\hline Duration of infertility & Number of patients & Pregnancy positive & Clinical preg. (+ve at 6 weeks) & OP \\
\hline $1-3$ & $241(23.6 \%)$ & $96(39.8 \%)$ & $76(31.5 \%)$ & $65(27 \%)$ \\
$3-6$ & $332(32.5 \%)$ & $132(39.8 \%)$ & $114(34.3 \%)$ & $100(30.1 \%)$ \\
$6-9$ & $223(21.9 \%)$ & $74(33.2 \%)$ & $53(23.8 \%)$ & $41(18.4 \%)$ \\
$9-12$ & $135(13.2 \%)$ & $49(36.3 \%)$ & $34(25.2 \%)$ & $32(23.7 \%)$ \\
$>12$ & $89(8.7 \%)$ & $29(32.6 \%)$ & $18(20.2 \%)$ & $15(16.9 \%)$ \\
\hline Total & $1020(100 \%)$ & $380(100 \%)$ & $295(100 \%)$ & $253(100 \%)$ \\
\hline
\end{tabular}

Chart 3

\begin{tabular}{lllll}
\hline Previous pregnancy outcome & Number of patients & Pregnancy positive & Clinical preg. (+ve at 6 weeks) & OP \\
\hline Nil & $720(70.6 \%)$ & $271(37.6 \%)$ & $207(28.8 \%)$ & $180(25 \%)$ \\
Abortion & $190(18.6 \%)$ & $75(39.5 \%)$ & $61(32.1 \%)$ & $52(27.4 \%)$ \\
Ectopic & $58(5.7 \%)$ & $15(25.9 \%)$ & $13(22.4 \%)$ & $9(15.5 \%)$ \\
Live birth & $43(4.2 \%)$ & $14(32.6 \%)$ & $12(27.9 \%)$ & $10(23.3 \%)$ \\
Death & $4(0.4 \%)$ & $2(50 \%)$ & $1(25 \%)$ & $1(25 \%)$ \\
\hline Total & $1020(100 \%)$ & $380(100 \%)$ & $295(100 \%)$ & $253(100 \%)$ \\
\hline
\end{tabular}

Chart 4

\begin{tabular}{lllll}
\hline Basal AFC & Number of patients & Pregnancy positive & Clinical preg. (+ve at 6 weeks) & OP \\
\hline$<5$ & $106(10.4 \%)$ & $20(18.9 \%)$ & $16(15.1 \%)$ & $13(12.3 \%)$ \\
$6-10$ & $307(30.1 \%)$ & $96(31.3 \%)$ & $76(24.8 \%)$ & $64(20.8 \%)$ \\
$11-15$ & $226(22.2 \%)$ & $123(54.4 \%)$ & $92(40.7 \%)$ & $76(33.6 \%)$ \\
$>15$ & $381(37.4 \%)$ & $141(37 \%)$ & $111(29.1 \%)$ & $100(26.2 \%)$ \\
\hline Total & $1020(100 \%)$ & $380(100 \%)$ & $295(100 \%)$ & $253(100 \%)$ \\
\hline
\end{tabular}

Chart 5

\begin{tabular}{lllll}
\hline Basal FSH & Number of patients & Pregnancy positive & Clinical preg. (+ve at 6 weeks) & OP \\
\hline$<3$ & $218(21.4 \%)$ & $79(36.2 \%)$ & $68(31.2 \%)$ & $53(24.3 \%)$ \\
$3-7.9$ & $649(63.6 \%)$ & $256(39.4 \%)$ & $196(30.2 \%)$ & $172(26.5 \%)$ \\
$8-11.9$ & $128(12.5 \%)$ & $35(27.3 \%)$ & $24(18.8 \%)$ & $22(17.2 \%)$ \\
$>12$ & $25(2.5 \%)$ & $10(40 \%)$ & $7(28 \%)$ & $6(24 \%)$ \\
\hline Total & $1020(100 \%)$ & $380(100 \%)$ & $295(100 \%)$ & $253(100 \%)$ \\
\hline
\end{tabular}

Chart 6

\begin{tabular}{lllll}
\hline Basal E2 & Number of patients & Pregnancy positive & Clinical preg. (+ve at 6 weeks) & OP \\
\hline$<40.0$ & $575(56.4 \%)$ & $215(37.4 \%)$ & $168(29.2 \%)$ & $146(25.4 \%)$ \\
$40-80$ & $387(37.9 \%)$ & $147(38 \%)$ & $112(28.9 \%)$ & $94(24.3 \%)$ \\
$>80$ & $58(5.7 \%)$ & $18(31 \%)$ & $15(25.9 \%)$ & $13(22.4 \%)$ \\
\hline Total & $1020(100 \%)$ & $380(100 \%)$ & $295(100 \%)$ & $253(100 \%)$ \\
\hline
\end{tabular}

Chart 7

\begin{tabular}{lllll}
\hline E2 on $h$ CG & Number of patients & Pregnancy positive & Clinical preg. (+ve at 6 weeks) & OP \\
\hline$<1000$ & $69(6.8 \%)$ & $12(17.4 \%)$ & $10(14.5 \%)$ & $9(13 \%)$ \\
$1000-2000$ & $300(29.4 \%)$ & $101(33.7 \%)$ & $76(25.3 \%)$ & $58(19.3 \%)$ \\
$2001-3000$ & $220(21.6 \%)$ & $91(41.4 \%)$ & $75(34.1 \%)$ & $65(29.5 \%)$ \\
$3001-4000$ & $161(15.8 \%)$ & $56(34.8 \%)$ & $43(26.7 \%)$ & $37(23 \%)$ \\
$>4000$ & $270(26.5 \%)$ & $120(44.4 \%)$ & $91(33.7 \%)$ & $84(31.1 \%)$ \\
\hline Total & $1020(100 \%)$ & $380(100 \%)$ & $295(100 \%)$ & $253(100 \%)$ \\
\hline
\end{tabular}




\section{Chart 8}

\begin{tabular}{lll}
\hline Cause of infertility & Number of patients & Pregnancy positive \\
\hline Ovulatory & $116(11.4 \%)$ & $56(48.3 \%)$ \\
Male factor & $339(32.6 \%)$ & $131(39.0 \%)$ \\
Endometriosis & $144(14.1 \%)$ & $50(34.7 \%)$ \\
Unexplained & $147(14.4 \%)$ & $59(40.1 \%)$ \\
Tubal & $87(8.5 \%)$ & $33(37.9 \%)$ \\
Pelvic & $101(9.9 \%)$ & $27(26.7 \%)$ \\
Diminished Ovarian & $50(4.9 \%)$ & $7(14 \%)$ \\
reserve & & \\
Multiple & $32(3.1 \%)$ & $16(50 \%)$ \\
\hline Sexual & $4(0.4 \%)$ & $1(25 \%)$ \\
\hline
\end{tabular}

threshold value ( $89 \%$ specificity and $56 \%$ sensitivity with threshold of $7.9 \mathrm{mIU} / \mathrm{ml})$.

Speroff et al showed measurement of both FSH and E2 on cycle day 3 increase likelihood of detecting poor OR and decreased chance of pregnancy. Thus, it may help to diminish the incidence of false-negative tests based on measurement of FSH alone. In present study, $43 \%$ of women with normal basal FSH and poor response ( 3 or less oocytes), had basal E2 $>80 \mathrm{pg} / \mathrm{ml}$. When both markers are precociously elevated, ovarian response is likely to be very poor, ${ }^{31}$ as was seen in one woman in the index study.

Chart 9

\begin{tabular}{lllll}
\hline Previous IVF outcome & Number of patients & Pregnancy positive & Clinical preg. (+ve at 6 weeks) & OP \\
\hline ND & $737(72.3 \%)$ & $290(39.3 \%)$ & $215(29.2 \%)$ & $188(25.5 \%)$ \\
Negative & $216(21.2 \%)$ & $67(31 \%)$ & $58(26.9 \%)$ & $49(22.7 \%)$ \\
Positive & $67(6.6 \%)$ & $23(34.3 \%)$ & $22(32.8 \%)$ & $16(23.9 \%)$ \\
\hline Total & $1020(100 \%)$ & $380(100 \%)$ & $295(100 \%)$ & $253(100 \%)$ \\
\hline
\end{tabular}

Chart 10

\begin{tabular}{lllll}
\hline LH on day of HCG & Number of patients & Pregnancy positive & Clinical preg. (+ve at 6 weeks) & OP \\
\hline$<1.0$ & $114(11.2 \%)$ & $51(44.7 \%)$ & $44(38.6 \%)$ & $39(34.2 \%)$ \\
$1.0-5.0$ & $883(86.6 \%)$ & $319(36.1 \%)$ & $243(27.5 \%)$ & $207(23.4 \%)$ \\
$>5.0$ & $23(2.3 \%)$ & $10(43.5 \%)$ & $8(34.8 \%)$ & $7(30.4 \%)$ \\
\hline Total & $1020(100 \%)$ & $380(100 \%)$ & $295(100 \%)$ & $253(100 \%)$ \\
\hline
\end{tabular}

Chart 11

\begin{tabular}{lllll}
\hline P4 on day of HCG & Number of patients & Pregnancy positive & Clinical preg. (+ve at 6 weeks) & OP \\
\hline$<1$ & $695(68.1 \%)$ & $260(37.4 \%)$ & $209(30.1 \%)$ & $178(25.6 \%)$ \\
$1-3$ & $295(28.9 \%)$ & $113(38.3 \%)$ & $82(27.8 \%)$ & $72(24.4 \%)$ \\
$>3$ & $30(2.9 \%)$ & $7(23.3 \%)$ & $4(13.3 \%)$ & $3(10 \%)$ \\
\hline Total & $1020(100 \%)$ & $380(100 \%)$ & $295(100 \%)$ & $253(100 \%)$ \\
\hline
\end{tabular}

Chart 12

\begin{tabular}{|c|c|c|c|c|}
\hline Endometrial thickness & Number of patients & Pregnancy positive & Clinical preg. (+ve at 6 weeks) & $O P$ \\
\hline$<7.0$ & $28(2.7 \%)$ & $11(39.3 \%)$ & $9(32.1 \%)$ & $9(32.1 \%)$ \\
\hline $7-8$ & $224(22 \%)$ & $74(33 \%)$ & $50(22.3 \%)$ & $44(19.6 \%)$ \\
\hline $8-9$ & $263(25.8 \%)$ & $104(39.5 \%)$ & $73(27.8 \%)$ & $62(23.6 \%)$ \\
\hline $9-10$ & $253(24.8 \%)$ & $93(36.8 \%)$ & $76(30 \%)$ & $65(25.7 \%)$ \\
\hline $10-11$ & $132(12.9 \%)$ & $51(38.6 \%)$ & $46(34.8 \%)$ & $39(29.5 \%)$ \\
\hline $11-12$ & $77(7.5 \%)$ & $32(41.6 \%)$ & $27(35.1 \%)$ & $20(26 \%)$ \\
\hline $12-13$ & $25(2.5 \%)$ & $11(44 \%)$ & $10(40 \%)$ & $10(40 \%)$ \\
\hline $13-14$ & $13(1.3 \%)$ & $3(23.1 \%)$ & $3(23.1 \%)$ & $3(23.1 \%)$ \\
\hline$>14$ & $5(0.5 \%)$ & $1(20 \%)$ & $2(40 \%)$ & $2(40 \%)$ \\
\hline Total & $1020(100 \%)$ & $380(100 \%)$ & $295(100 \%)$ & $253(100 \%)$ \\
\hline \multicolumn{5}{|c|}{ Chart 13} \\
\hline Ovarian response & $\begin{array}{l}\text { Number of patients } \\
(n=1020)\end{array}$ & $\begin{array}{l}\text { Pregnancy positive } \\
(n=380)\end{array}$ & $\begin{array}{l}\text { Clinical preg. (+ve at } 6 \text { weeks) } \\
(n=295)\end{array}$ & $O P(n=253)$ \\
\hline \multicolumn{5}{|l|}{ Total follicles } \\
\hline - Hyper response $>12$ & $364(35.7 \%)$ & $167(45.9 \%)$ & $125(34.3 \%)$ & $114(31.3 \%)$ \\
\hline - Good response 4-12 & $587(57.5 \%)$ & $200(34.1 \%)$ & $159(27.1 \%)$ & $132(22.5 \%)$ \\
\hline - Poor response < 4 & $69(6.8 \%)$ & $13(18.8 \%)$ & $11(15.9 \%)$ & $7(10.1 \%)$ \\
\hline \multicolumn{5}{|l|}{ M II oocytes } \\
\hline - Hyper response $>12$ & $272(26.7 \%)$ & $130(47.8 \%)$ & $105(38.6 \%)$ & $96(35.3 \%)$ \\
\hline - Good response 4-12 & $593(58.1 \%)$ & $225(37.9 \%)$ & $173(29.2 \%)$ & $147(24.8 \%)$ \\
\hline - Poor response <4 & $155(15.2 \%)$ & $24(15.5 \%)$ & $17(11 \%)$ & $10(6.5 \%)$ \\
\hline
\end{tabular}


Frattarelli et al ${ }^{25}(2000)$ showed patients with elevated E2 levels were more likely to respond poorly to gonadotropins but in this study only $31 \%$ with high and $37.4 \%$ with low basal E2 levels had poor response. Higher rates of cancelled ART cycles have demonstrated with E2 levels $<20 \mathrm{pg} / \mathrm{ml}$ or $\geq 80 \mathrm{pg} / \mathrm{ml}$, whereas among $4.1 \%$ cancelled cycles in this study, $2 \%$ had basal E2 $<40 \mathrm{pg} / \mathrm{ml}$ or $>80 \mathrm{pg} / \mathrm{ml}$.

Fic Icioglu et $\mathrm{al}^{26}$ have also demonstrated similar basal E2 levels in serum of good and poor responders to gonadotropin stimulus in ART cycles as in this study. However, other studies favorable to the use of E2 as an ovarian reserve marker have been incapable to correlate it to the follicular development or demonstrate its ability to predict the occurrence of pregnancy. ${ }^{25,27-29}$

According to the study of Muttukrishna et al, ${ }^{33}$ AFC allows identification of poor response with $89 \%$ sensitivity, in spite of low specificity compared to $100 \%$ sensitivity and $89 \%$ specificity in this study, and other authors admit its importance as a screening test for infertile couples. ${ }^{19}$

In women with $\mathrm{AFC} \geq 4$, Gibreel et $\mathrm{al}^{32}$ reported $98.7 \%$ pregnancies compared to $97 \%$ in present study. In women with $<4$ AFC, cycle cancellation was seen on 2 patients and $10 \%$ continued pregnancy. AFC must not be used as a criterion for ART exclusion, but as a tool for counseling on the low probability of achieving pregnancy and determining individualized treatment protocols in IVF cycles.

According to Maseelall et al, ${ }^{35}$ women with AFC $\geq 11$ (follicles measuring between 2 and $10 \mathrm{~mm}$ present on both ovaries) are more likely to obtain a live birth if compared with those with less antral follicles, who should be advised about the increased risk of miscarriages but there was no difference in ongoing pregnancies in women with $<$ or $>11 \mathrm{AFC}$ in this study.

Verhagen in a multivariate analysis found $\mathrm{AFC}$ was the single best predictor of ovarian response with significant superiority in relation to other markers. ${ }^{31}$ The prognosis, with FSH has a small additive effect. ${ }^{30}$ But in the present study, logistic regression analysis was used to predict pregnancy and $\mathrm{AFC}$ was not a significant predictor.

\section{CONCLUSION}

This was an attempt to create a composite scoring for predicting the outcome of IVF by making the most of routinely collected data, applying sophisticated statistical modeling and using the output to provide quantitative estimate of couple's chance of success.

Through the study, 14 variables were looked into (on patient characteristics, clinical diagnoses, treatment response) and association of each variable with IVF outcomes was examined. Outcomes were defined by chemical, clinical and ongoing pregnancy. Going beyond previous studies, the interrelation/association between various factors was also assessed. It was found that some of the variables were redundant, while some others were critical in predicting ART outcome. This study found that factors - age, duration of infertility, basal FSH, and serum E2 on day of hCG were most important in a woman's chance of becoming pregnant. These variables may prove 'critical in counseling patients, maximizing cost-effectiveness and minimizing inconvenience and risk for the patient, improving treatment and ultimately in developing more customized treatments'. These factors will someday help doctors to counsel those patients trying to decide whether to go for another IVF cycle and to give a more accurate prediction. There may be an opportunity to save vital resources if a couples chances of success were deemed too minute.

Prospective validation is required before this prediction model can be introduced into routine clinical practice to obtain high degree of treatment individualization.

\section{AUTHORS' ROLE}

RG collected all cases, supervised the statistical analysis and interpretation, wrote the article and prepared the Tables 1 to 3 and Charts 1 to 13, drafted the manuscript, and edited the final document. FLT reviewed the cases, contributed to the drafting and edi-ting of the article and performed laparoscopic surgery. PG conceived and designed the study. He also provided access to patient data.

All authors read and approved the final manuscript.

\section{ACKNOWLEDGMENTS}

We thank Dr KK Gopinathan for useful comments on the manuscript. We also thank the Dr MS Kokila for the initiative toward this dissertation. We are indebted to all the couples who participated and contributed to the study. Mr Deepak, statistician for the statistical analysis.

\section{REFERENCES}

1. Templeton A, Fraser C, Thompson B. Infertility - epidemiology and referral practice. Hum Reprod 1991;6(10):1391-1394.

2. De Mouzon J. IVF monitoring worldwide (ICMART). 22nd Annual Meeting of the ESHRE, Prague, Czech Republic, 18-21 June 2006, Abstract 0-193.

3. Nyboe Andersen A, Goossens V, Gianaroli L, Felberbaum R, de Mouzon J, Nygren KG. Assisted reproductive technology in Europe, 2003. Results generated from European registers by ESHRE. Hum Reprod 2007;22(6):1513-1525.

4. Scott RT Jr, Hoffmann GE. Prognostic assessment of ovarian reserve. Fertile Steril 1995 Jan;63(1):1-11.

5. Lass A, Brinsden P. The role of ovarian volume in reproductive medicine. Hum Reprod Update 1999 May-June;5(3):256-266.

6. Syrop CH, Dawson JD, Husman KJ, Sparks AE, Van Voorhis BJ. Ovarian volume may predict assisted reproductive outcomes better than follicle stimulating hormone concentration on day 3. Hum Reprod 1999 Jul:14(7):1752-1756. 
7. Ng EH, Chan CC, Tang OS, Ho PC. Antral follicle count and FSH concentration after clomiphene citrate challenge test on the prediction of ovarian response during OVF treatments. Hum Reprod 2005 Jun;20(6):1647-1654.

8. Kupesic S, Kurjak A. Predictors of IVF outcome by threedimensional ultrasound. Hum Reprod 2002 Apr;17(4):950-955.

9. Engmann L, Sladkevicius P, Agarwal R, Bekir JS, Campbell S, Tan SL. Value of ovarian stromal blood flow velocity measurement after pituitary suppression in the prediction of ovarian responsiveness and the outcome of in vitro fertilization treatment. Fertil Steril 1999 Jan;71(1):22-29.

10. Bancsi LF, Hujis AM, den Ouden CT, Broekmans FJ, Looman CW, Blankenstein MA, Te Velde ER. Basal follicle-stimulating hormone levels are of limited value in predicting ongoing pregnancy rates after in vitro fertilization. Fertile Steril 2000 Mar;73(3):552-557.

11. Noci I, Biagiotti R, Maggi M, Ricci F, Cinotti A, Scarselli G. Low day 3 luteinizing hormone values are predictive of reduced response to ovarian stimulation. Hum Reprod 1998 Mar;13(3): 531-534.

12. Eldar-Geva T, Ben-Chetrit A, Spitz IM, Rabinowitz R, Markowitz E, Mimoni T, Gal M, Zylber-Haran E, Magalioth EJ. Dynamic assays of inhibin B, anti-mullerian hormone and estradiol following FSH stimulation and ovarian ultrasonography as predictors of IVF outcome. Hum Reprod 2005 Nov;20(11): 3178-3183.

13. Kupka MS, Dorn C, Richter O, Felberbaum R, Van der Ven $\mathrm{H}$. Impact of reproductive history on in vitro fertilization and intra-cytoplasmic sperm injection outcome: evidence from the German IVF Registry. Fertil Steril 2000 Sep;74(3):508-516.

14. Frattarelli JL, Bergh PA, Drews MR, Sharara FI, Scott RT. Evaluation of basal estradiol levels in assisted reproductive technology cycles. Fertil Steril 2000 Sep;74(3):518-524.

15. El-Nemr A, Al-Shawaf T, Sabatini L, Wilson C, Lower AM, Grudzinskas JG. Effect of smoking on ovarian reserve and ovarian stimulation in in vitro fertilization and embryo transfer. Hum Reprod 1998 Aug;13(8):2192-2198.

16. Balakier H, Bouman D, Sojecki A, Librach C, Squire JA. Morphological and cytogenetic analysis of human giant oocytes and giant embryos. Hum Reprod 2002;17:2394-2401.

17. Ng EH, Tang OS, Ho PC. The significance of the number of antral follicles prior to stimulation in predicting ovarian responses in an IVF programme. Hum Reprod 2000 Sep;15(9):1937-1942.

18. Huang JYJ, Rosenwaks Z. In vitro fertilisation treatment and factors affecting success. Best Prac and Res Clin Obstet and Gynaecol 2012;26:777-788.

19. Broekmans FJ, Kwee J, Hendriks DJ, et al. A systematic review of tests predicting ovarian reserve and IVF outcome. Hum Reprod Update 2006;12(6):685-718.

20. Spandorfer SD, Chung PH, Kligman I, et al. An analysis of the effect of age on implantation rates. J Assist Reprod Genet 2000; 17(6):303-306.

21. Spandorfer SD, Bendikson K, Dragisic K, et al. Outcome of in vitro fertilization in women 45 years and older who use autologous oocytes. Fertil Steril 2007;87(1):74-76.

22. Popovic-Todorovic B, Loft A, Bredkjner HE, Bangsbull S, Nielsen IK, Andersen AN. A prospective randomized clinical trial comparing an individual dose of recombinant FSH based on predictive factors $v s$ a standard dose of $150 \mathrm{IU} /$ day in standard patients undergoing IVF/ICSI treatment. Hum Reprod 2003;18(11):2275-2282.

23. Roberts JE, Spandorfer S, Fasouliotis SJ, et al. Taking a basal follicle stimulating hormone history is essential before initiating in vitro fertilization. Fertil Steril 2005;83(1):37-41.

24. Speroff L, Fritz MA. Female infertility, in clinical gynaecologic endocrinology and infertility. Speroff L, Fritz MA, editors. p. 1015-1022. Lippincott Williams and Wilkins, Philadelphia, Pa, USA. 7th ed, 2005.

25. Fratarelli JL, Bergh PA, Drews MR, Sharara FI, Scott RT Jr. Evaluation of basal estradiol levels in assisted reproductive technology cycles. Fertility and Sterility 2000;74(3):518-524.

26. Iciogli CF, Kutlu T, Baglam E, Nakacak Z. Early follicular anti mullerian hormone as an indicator of ovarian reserve. Fertility Sterility 2006;85(3):592-596.

27. Licciardi FL, Liu HC, Rosenwaks Z. Day 3 estradiol serum concentrations as prognosticators of ovarian stimulation response and pregnancy outcome in patients undergoing in vitro fertilization. Fertility and Sterility 1995;64(5):991-994.

28. Smotrich DB, Levy MJ, Widra EA, Hall JL, Gindoff PR, Stillman RJ. Prognostic value of day 3 estradiol on in vitro fertilization outcome. Fertility and Sterility 1995;64(6):1136-1140.

29. de Carvalho BR, Silva ACJDSRE, Silva JCRE, Reis RMD, Ferriani RA, Silva De Sá MF. Use of ovarian reserve markers and variables of response to gonadotropic stimulus as predictors of embryo implantation in ICSI cycles. Journal Brasileiro de Reproducao Assistida 2009;13(3):26-29.

30. Bancsi LFJMM, Broekmans FJM, Eijkemans MJC, de Jong FH, Habbema JD, Te Velde ER. Predictors of poor ovarian response in invitro fertilization: a prospective study comparing basal markers of ovarian reserve. Fertility and Sterility 2002;77(2): 328-336.

31. Verhagen TEM, Hendriks DJ, Bancsi LFJMM, Mol BWJ, Broekmans FJM. The accuracy of multivariate models predicting ovarian reserve and pregnancy after in vitro fertilization: a metaanalysis. Human Reproduction Update 2008;14(1):95-100.

32. Gibreel A, Maheshwari A, Bhattacharya S, Johnson NP. Ultrasound tests of ovarian reserve; a systematic review of accuracy in predicting fertility outcomes. Human Fertility 2009;12(2):95-106.

33. Muttukrishna S, McGarrigle H, Wakim R, Khadum I, Raniero DM, Serhal P. Antral follicle count, anti-Mullerian hormone and inhibin B: predictors of ovarian response in assisted reproductive technology. Int J Obstet Gynaecol 2005;112(10):1384-1390.

34. Elgindy EA, El-Haieg DO, El-Sabaey A. Anti-Mullerian hormone: correlation of early follicular. Ovulatory and mid luteal levels with ovarian response and cycle outcome in intracytoplasmin sperm injection patients. Fertility and Sterility 2008;89(6):1670-1676.

35. Maseelall PB, Hernandez-Rey AE, Oh C, Maagdenberg T, McCulloh DH, McGovern PG. Antral follicle count is a significant predictor of live birth in in vitro fertilization cycles. Fertility and Sterility 2009;91(4):1595-1597.

36. Croucher CA, Lass A, Margara R, Winston RM. Predictive value of the results of a first in vitro fertilization cycle on the outcome of subsequent cycles. Hum Reprod 1998;13(2):403-408.

37. Assisted Reproductive Technology Success Rates: National Summary and Fertility Clinic Reports 2009. National Centre for Chronic Disease Prevention and Health Promotion. 